Notas Clínicas

\title{
Metástasis ovárica de melanona maligno de tumor primario de origen desconocido
}

\author{
R. Guarch*, F. García Bragado*, N. Lainez*, A. Lara*, C. Pesce**
}

\begin{abstract}
Resumen
La habilidad del melanoma maligno metastásico para asumir una amplia variedad de patrones morfológicos, incluyendo distintos tipos de sarcoma es bien conocida. Las metástasis de melanoma maligno en ovario, cuando se presentan como tumor primitivo ovárico son un hecho excepcional. Presentamos en este artículo un caso inusual de metástasis unilateral de melanoma maligno, sin una evidencia clínica de tumor primario. Se discute la historia clínica y el diagnostico diferencial . La paciente presentó una tumoración ovárica de $12 \mathrm{~cm}$, acompañada de un nódulo en meso de colon transverso de $2 \mathrm{~cm}$, ambos presentaban una superficie lobulada. En algunas áreas y particularmente en el ovario, la morfología del tumor era predominatemente epitelioide y el patrón de crecimiento periteliomatoso. En el mesenterio la morfología era predominantemente fusocelular y su apariencia recordaba a un tumor maligno de vaina nerviosa periférica, incluyendo areas de necrosis geográfica. Las células tumorales expresaron vimentina, HMB-45, actina y S-100 (difusa). La distribución de los nódulos tumorales, la combinación de patrones mortológicos, y el perfil inmunohistoquímico es consistente con el diagnóstico de metastasis de melanoma maligno.
\end{abstract}

Palabras clave:

Melanoma maligno. Ovario. Metástasis.

Oncología, 2004; 27 (3):131-134

* Servicio de Anatomía Patológica y Ginecología Hospital Virgen del Camino

** Servicio de Oncología del Hospital de Navarra

Pamplona. España.

DISTBIMO*. University of Genova Medical School, Genova, Italy 


\section{Summary}

The capacity of malignant melanoma to develop a variety of histologic appearances, including those of various types of sarcomas, is well known. Malignant melanoma metastases to the ovary presented as a primary ovarian tumor are exceptional. We report an unusual case of unilateral ovarian metastatic malignant melanoma without clinical evidence of primary lesion. The clinical history and the pathological differential diagnosis are discussed. The patient presented an enlarged right ovary $(12 \mathrm{~cm})$ and a mesentery node $(2 \mathrm{~cm})$, both of them with a lobulated surface. Some areas, particularly in the ovary, showed tumor cells of epithelioid appearance with a striking peritheliomatous growth pattern. The mesentery node was completely different, showing a predominantly spindle-cell shaped aspect reminiscent of a malignant peripheral nerve sheath tumor, including geographic necrosis areas. The neoplastic cells stained positively with HMB-45, vimentin, actin and S-100 (diffusely). The distribution of the tumor node, the combination of the cell pattern and the immunohistochemical profile were consistent with a metastatic melanoma.

Key words: Malignant melanoma. Ovary. Metastases.

\section{Introducción}

El diagnóstico de metástasis de melanoma maligno puede ser dificil cuando se presenta en tejidos blandos y esto se debe a la gran variabilidad de patrones morfológicos que este tumor puede asumir, pudiendo simular otros tumores como carcinomas, sarcomas o más raramente linfomas. Aunque existe cierta dificultad en el diagnóstico anatomopatológico de las metástasis ováricas, en en la literatura se observa un número escaso de trabajos que hacen referencia al diagnóstico de la metástasis de melanoma maligno en el ovario ${ }^{1,2}$.

En este artículo se presenta un caso de metástasis ovárica de melanoma maligno que debutó como tumor primitivo ovárico, destacando en este caso el diagnóstico diferencial y su evolución.

\section{Caso clínico}

Mujer de 24 años de edad, drogadicta, HIV negativo, con historia desde hace 9 meses de infiltrados nodulares pulmonares con diagnóstico clínico de posible granulomatosis. Debutó hace 1 mes con fiebre y dolor abdominal por masa anexial derecha. En la exploración se vió una masa ovárica derecha de $12 \mathrm{~cm}$, junto a otra en meso de colon transverso de $2 \mathrm{~cm}$ que se extirparon. Simultáneamente la paciente refería una tumoración en muslo derecho de $4 \mathrm{~cm}$, localizada en profundidad del tejido celular subcutaneo

El tumor ovárico y el nódulo mesentérico presentaban una superficie externa lobulada, cuya superficie de sección mostraba areas sólidas y quísticas. En el ovario, las células presentaban predominantemente una morfología epitelioide con nucleolo prominente y patrón de crecimiento difuso con pequeñas espacios quísticos o seudofoliculos (Fig 1). En el nódulo mesentérico predominaba una morfología fusocelular (Fig 2). Se observaban areas alternativas hipercelulares e hipocelulares. Existian extensas y frecuentes areas de necrosis geográfica con tendencia a preservar aquellas células tumorales que rodeaban a los vasos resultando en un patrón periteliomatoso (Fig 3). A mayor aumento, las células tumorales fusiformes mostraban nucleo oval y nucleolo no prominente. Se observaban más de 10-20 mitosis por 10 campos de gran aumento. Inmunofenotípicamente el tumor expresó vimentina, S-100, HMB-45 y actina. La tinción para S-100 era intensa y difusa (Fig 4). El tumor no expresaba marcadores epiteliales ni otros marcadores como CD 117 , CD 68, CD 99, colágeno IV, receptores de estrógenos,

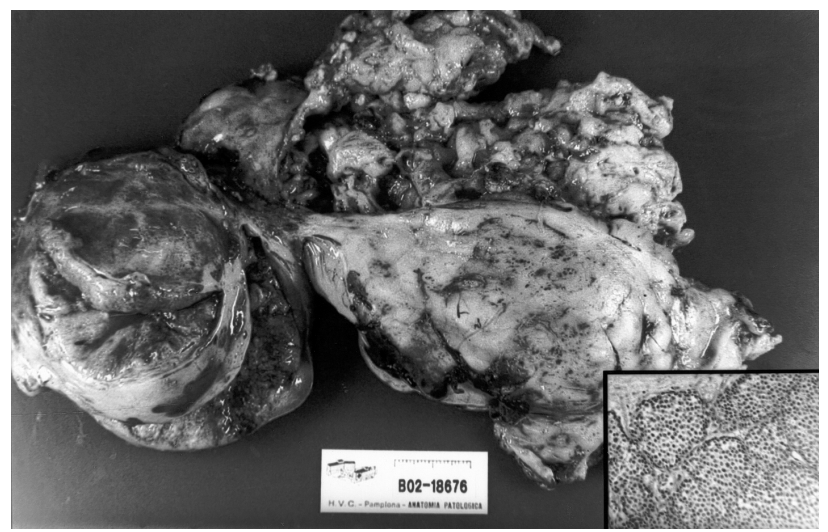

Fig. 1. Tumoración ovárica derecha con extensas areas de necrosis. Detalle: predominio de morfología epitelioide de las células tumorales. 


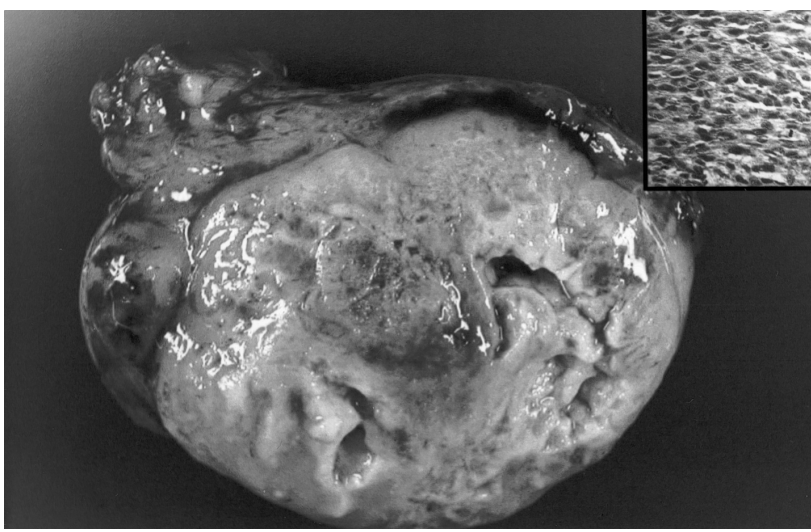

Fig. 2. Nódulo de mesenterio cuya superficie de sección muestra areas sólidas y quísticas. Detalle: predominio de morfología fusocelular de las células tumorales.

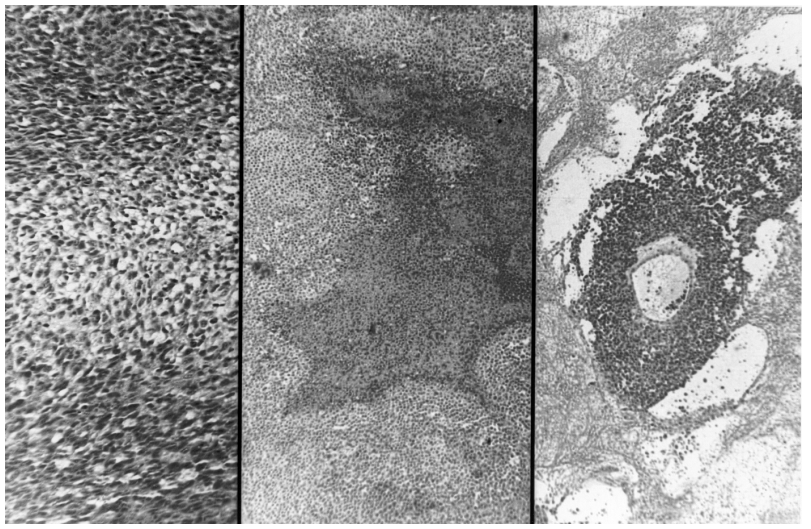

Fig. 3. Areas alternantes de hipercelularidad e hipocelularidad (izquierda), areas de necrosis geográfica (centro) y patrón periteliomatoso (derecha).

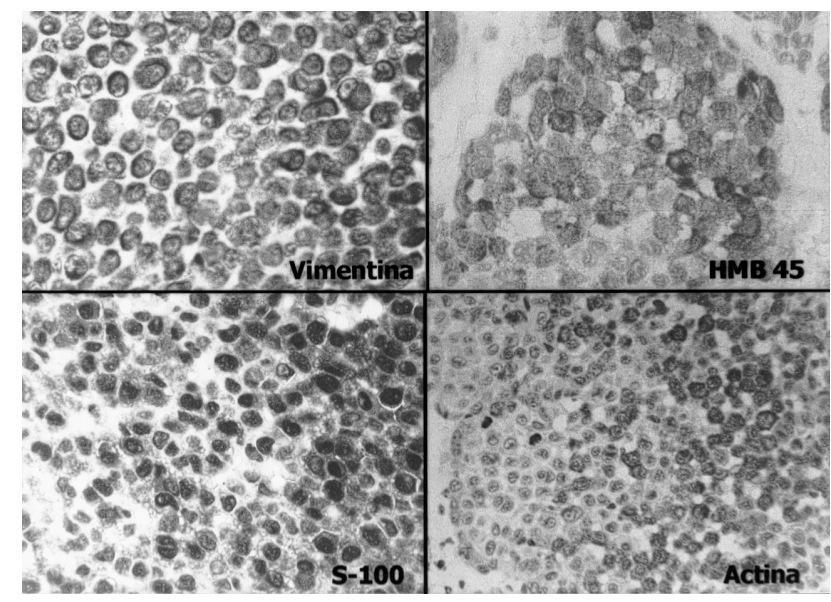

Fig. 4. Inmunofenotípicamente, el tumor expresa vimentina, HMB-45, S-100 y actina.

receptores de progesterona e inhibina. El tumor del muslo extirpado posteriormente no tenía relación con la epidermis e histológicamente era superponible al tumor ovárico. La distribución de los nódulos tumorales, la combinación de patrones histológicos y el perfil inmunohistoquímico fué consistente con el diagnóstico de melanoma maligno metastásico, originado sobre un tumor primario de origen desconocido ya que la paciente fue explorada y no se encontró ninguna lesión pigmentada preocupante ni existian datos de regresión de una de ellas.

Se instauró el tratamiento con quimioterapia (Cisplatino, Interleukina II, Dacarbacina e Interferon alfa) y 3 meses más tarde, la paciente falleció desarrollando metástasis abdominales multiples, entre ellas masa ovárica contralateral de $13 \mathrm{~cm}$, adenopatias retroperitoneales y metástasis subcutaneas múltiples.

\section{Discusión}

Las metástasis ováricas de melanoma maligno se producen por diseminación hematógena en el 15\% de las mujeres que mueren por este tumor. La forma de presentación en este caso es muy infrecuente, ya que ocasionálmente estos tumores pueden presentarse como tumor primitivo ovárico, refiriéndose unicamente menos de 50 casos en la literatura ${ }^{1,2,3,4}$. Pueden aparecer incluso hasta 25 años después de que la lesión primaria fuera extirpada. Los melanomas malignos primitivos de ovario son muy raros ${ }^{5}$ y se presentan habitualmente en el contexto de un teratoma.

La presentación bilateral sugiere el que se trate de una metástasis. Por otra parte, las metástasis ováricas de melanoma maligno han sido descritas como unilaterales en el $50 \%$ de y $60 \%$ de las series más largas ${ }^{1,2}$. La unilateralidad no excluye la posibilidad de una metástasis ${ }^{6}$. En este caso aunque la presentación fue unilateral, posteriormente la paciente desarrolló una masa ovárica contralateral.

En las series más largas de melanoma maligno metastásico, el número de casos en los que no se ha encontrado un tumor primario oscila entre un $2-6 \%$, con artículos aislados que refieren dicha frecuencia hasta un $15 \% 7,8$.

El diagnóstico se complica cuando se trata de un melanoma maligno amelanótico, con rasgos morfológicos similares a otros tipos de tumores. El melanoma maligno es el gran simulador?. En tales casos, la verdadera naturaleza del tumor se reconoce por la presencia concomitante de focos de tumor convencional en el tumor primario o en la metástasis. En este caso el tumor ovárico mostró areas de crecimiento en forma de nidos que podian sugerir melanoma. La tinción para S- 100 y HMB- 45 así como o la ultraestructura son los elementos útiles para el diagnóstico. 


\section{R. Guarch y cols.}

El diagnóstico diferencial de tumores ováricos con células epitelioides es amplio e incluye ciertos tumores primario y metastásicos tal como tumor de células esteroideas, variante oxífila de carcinoma de células claras, variedad de células grandes de carcinoma de células pequeñas, carcinoma hepatoide, variedad hepatoide del tumor del seno endodermico, tumor de células de la granulosa variedad juvenil, linfoma de células grandes o disgerminoma. La presencia de un patrón de crecimiento fusocelular en dichas metástasis pueden sugerir un diagnóstico de sarcoma' ${ }^{1}$.

En este caso se plantea el diagnóstico diferencial entre metástasis de melanoma y un sarcoma. El algunas areas y particularmente en el ovario el patrón es muy epitelioide y el patrón de crecimiento es periteliomatoso. En el nódulo del meso las células son predominantemente fusocelulares y su apariencia recuerda a un tumor maligno de vaina nerviosa periférica (MPNST) incluyendo areas con necrosis geográfica.

King y cols. ${ }^{10}$ consideran el diagnóstico de metástasis de melanoma en un tumor maligno con un patrón similar a un MPNST en el cual se dan alguna de las siguientes caracteristicas: localización dentro o en proximidad a un ganglio linfatico, ausencia de relación con un nervio, presencia de un melanoma primario o concomitante, expresión de HMB-45, y una expresión intensa y difusa para proteina S-100 (los MPNST, muestran tinción focal) ${ }^{11}$, cumpliéndose en este caso. Si no se encuentra un melanoma primario, se debe contemplar la posibilidad de regresión de melanoma. La similitud de este tumor con los MPNST están probablemente relacionada con su origen común neuroectodérmico $^{10}$.

Destaca en este caso la expresión de actina por el tumor, esto pudiera hacer pensar en tumores con diferenciación melanocítica y muscular, tal como los pecomas (sarcoma abdominopélvico de células perivasculares epitelioides $)^{12}$. Pero en esta paciente no se observó esclerosis tuberosa, y su morfología y comportamiento son muy diferentes. Por otra parte se ha visto que los melanomas pueden tener ocasionálmente expresión aberrante de citoqueratinas y marcadores musculares $^{13}$.

\section{Bibliografía}

1. Young RH and Scully R. Malignant melanoma metastatic to the ovary. A clinicopathologic analysis of 20 cases. Am J Surg Pathol. 1991;15:849-860.

2. Fitzgibbons PL Martin SE, Simmons TJ. Malignant melanoma metastaic to the ovary. Am J Surg Pathol. 1987;1 1:959-964.

3. Tribbia G, Pezzica E, Buzzi A, Cresceni C Sonzogni A. Metastatic malignant melanoma of the ovary .Minerva Ginecol. 1996;48:159-162.

4. Remedi S, McGee W, Egger JF, Ismail A. Ovarian metastatic melanoma. A diagnostic pitfall in histopathologic examination. Arch Anat Cytol Pathol. 1997;45:43-46

5. Shroff CP, Borges AM, Deodhan KP. Primary melanoma of the ovary in a 25 year primigravida. A case report. Tumori. 1989; 75:72-75.

6. Hsiu JG, Kemp GM, Given FT Jr, D`Amato NA. Malignant melanoma presenting as a unilateral ovarian neoplasia.Ginecol Oncol. 1986;24:362-366.

7. Schlagenhauff B, Stroebel W, Ellwanger V, et al. Metastatic melanoma of unknown primary origin shows prognostic similarities to regional metastatic melanoma. Recommendations for initial staging examination. Cancer. 1997;80:60-65.

8. Jonk A, Kroon BBR, Rumke PH, Mooi WJ, Hart AAM, Van Dougen JA. Lymph node metastasis from melanoma with an unknown primary site. Br J Surg. 1990;77:665668.

9. Nakhleh RE, Wick MR, Rocamora A, Swanson PE, Dehner LP.Morphologic diversity in malignant melanoma. Am J Clin Pathol. 1990;93:731-740.

10. King R, Busan K and Rosai J. Metastatic malignant melanoma resembling malignant peripheral nerve sheath tumor. Report of 16 cases. Am J Surg Pathol. 1999; 23: 1499-1505.

11. Woodruff JM. Pathology of the major peripheral nerve sheath neoplasms. International Academy of Pathology. Monograph, Soft Tissue Tumors. 1996;4:129-161.

12. Bonetti F, Martignoni $G$, Colato $\mathrm{CH}$, et al . Abdominopelvic sarcoma of perivascular epithelioid cells. Report of four cases in young women, one with tuberous sclerosis. Mod Pathol. 2001; 14:563-568.

13. Banerjee SS, Bishop PW, Nicholson CM. Malignant melanoma showing smooth muscle differentiation. J Clin Pathol. 1996;49:950-951.
Correspondencia:

Dra. R. Guarch

Servicio de Anatomía Patológica

Hospital Virgen del Camino

C/ Irunlarrea, 4

E-31008 Pamplona

E-mail: rosa.guarch.troyas@cfnavarra.es 